\title{
Basic Knowledge and Attitudes to Promote Safe Behaviours to Grade 8 Learners Concerning Burden of Diseases Including HIVIAIDS
}

\author{
P. Nqabeni \\ Department of Educational Sciences, Walter Sisulu University, Eastern Cape 5100, South Africa
}

\begin{abstract}
This paper focuses on knowledge and attitudes of Grade 8 pupils about HIV/AIDS and opportunistic diseases. In particular, people need to know what it is, how it is transmitted, how to protect themselves from it, and how to relate to people with the disease. According to the National policy for HIV/AIDS, schools are key settings for educating children about HIV/AIDS and for halting further spread of the infection. It has been noticeable that Grade 8 pupils in the rural areas around Mthatha district are particularly at risk of getting HIV. The focus is often more on Grade 11 and 12 pupils, so female Grade 10 pupils look for boys for attention. This resulted for the female pupils to fall pregnant. The fact that some of them are falling pregnant means they are also more vulnerable to contracting HIV. This shows that little information is available for them and this paper is contributing to that body of knowledge. Prevention therefore is the most effective strategy to combat pregnancy and against the spread of HIV/AIDS in schools. Measures should be taken to remove the social, cultural and political barriers that might block access to HIV/AIDS services and programmes. The results showed that while some Grade 8 pupils are aware of HIV/AIDS, there are others who said it does not exist. It has also been highlighted that the phenomenon of pupils having unprotected sex with older men for money, as well as pupils saying they did not have time to use condoms. It is therefore recommended that pupils need to have role models, people they can look up to. In the absence of parents, it should be teachers' responsibility to advise the pupils and inform them about Sexually Transmitted Infections (STIs) and HIV/AIDS in schools.
\end{abstract}

Key words: HIV/AIDS, knowledge, attitude, pregnant, diseases, opportunistic diseases.

\section{Introduction}

HIV/AIDS is not only a worldwide problem but also an African continent and South Africa's serious health and socio-economic problem [1]. Worldwide people including school children were infected with HIV/AIDS and were suffering from HIV/AIDS related diseases for instance, pneumonia, tuberculosis and diarrhoea. In addition, worldwide, 40 million adults and children are living with HIV/AIDS, and at least 10.4 million children currently under the age of 15 have lost one or both parents to Ref. [2] AIDS. This disease increasingly affects young people including school children.

Higher Education HIV/AIDS Programme [3], stated

Corresponding author: Pelokazi Nqabeni, doctor of education, research fields: HIV/AIDS. that the Acquired Immune Deficiency Syndrome (HIV/AIDS) impact assessment for schools in SA has revealed the infection levels of $2 \%$ and will reach $33 \%$ by 2005 . With respect to the number of learners with HIV/AIDS in 2000 around 0.7\% that had HIV/AIDS. South African children under 15 years of accounted for a third of the population 16.86 million. Also in the same year AIDS accounted for $43.6 \%$ of all deaths in SA and rendered 2.01 million children AIDS orphans (Statistics South Africa, 2012).

HIV/AIDS affects regret school children and their intellectual ability which may lead to, pregnancy, poor performance in their studies and dropout of school children [4]. This also affects the socio-economy because some people are not able to work and school children do not develop as they wish. This resulted to isolation, fear, death, misunderstandings and 
withdrawals of children from schools. Therefore, since there is no cure for HIV/AIDS and because it is transmitted by various ways including sexual contact, it is vital that everyone including school children knows about the disease. In particular, people need to know what it is, how it is transmitted, how to protect themselves from it, and how to relate to people with the disease.

In preventing the HIV/AIDS infection, the crucial responsibility of schools is to teach young people how to avoid either contracting the infection or transmitting it to others and to serve as a catalyst for the development of HIV/AIDS related policies based on the most current scientific knowledge [4]. In doing so, schools have the opportunity to make important improvements in the quality of health education provided to young people worldwide as a step towards improving global health.

Even though the National policy [5], committed itself on minimizing the pandemic, it has been noticeable that Grade 8 pupils in the rural senior secondary schools around Mthatha were particularly at risk. "When pupils move to senior secondary schools to start Grade 10 they are not given enough attention by teachers. The focus is often more on Grade 11 and 12 pupils, so female Grade 8 pupils look for boys for attention. This resulted for the female pupils to fall pregnant. The fact that some of them are falling pregnant means they are also more vulnerable to contracting HIV. This shows little information is available for them and this paper is contributing to that body of knowledge. Prevention therefore is the most effective strategy to combat pregnancy and against the spread of HIV/AIDS in schools. Measures should be taken to remove the social, cultural and political barriers that might block access to HIV/AIDS services and programmes.

According to Ref. [6], HIV/AIDS is a disease that threatens the lives of everybody including school children. Since there is no cure for HIV/AIDS, and because it is transmitted by various ways including sexual contact, it is vital that everyone including school children knows about the disease. In particular, people need to know what it is, how it is transmitted, how to protect themselves from it and how to relate to people with the disease. HIV/AIDS is not only a medical problem; it has psychological and economic implications.

Moreover, efforts have been made for example, the National policy for HIV/AIDS for schools (Government Gazette, 1999) [7], declared that the Ministry is committed to minimizing the, economic and developmental consequences of HIV/AIDS to the education system. According to the policy, schools are key settings for educating children about HIV/AIDS and for halting further spread of the infection. It is visualized that all learners and educators should be encouraged and trained in providing leadership to implement an HIV/AIDS policy in schools.

In South Africa, studies conducted by the Department of Education as well as international bodies show that the spread of HIV/AIDS is still continuing [8], and that learners in South African schools drop-out, perform poorly and fall pregnant. That means they do not lack knowledge and positive attitude to take the informed decisions about themselves not to get HIV. Ref. [9], states that HIV/AIDS has a traumatic impact in the classroom on both teachers and learners. Therefore, teachers have a duty to plan for emergencies that may include financial assistance to AIDS affected learners [8]. Consequently, the then Minister of Education [10], declared run a program on Life Skills on prevention of HIV and management of AIDS as part of the curriculum of the school.

The problem that HIV/AIDS is still uprising that confirms the findings of the study conducted of the Ref. [11], Journal for African Women's Students declares that Ref. [12] paints a gloomy picture of the HIV/AIDS situation in South Africa when it reports that "According to recent statistics released by Ref. [13], South Africa has the highest HIV/AIDS figures in the 
world". The report also stated that the pandemic in SA (South Africa) is spreading at a rate unknown in any other country.

This is confirmed the views expressed in the relevant literature reviewed by Ref. [14], indicated that South African school learners' levels are lower than those of their age groups from Tanzania, whose knowledge was also assessed by the SACMEQ Research Report.

\section{Objectives}

The main purpose of this paper is to promote the safe behaviours on basic knowledge and attitudes to Grade 8 learners concerning the burden of diseases including HIV/AIDS. Find out more about HIV/AIDS and attempt to bring about change in behavioural patterns of teachers and parents. This resulted from an observation that Grade 8 learners in rural areas around Mthatha District are particularly at risk of getting HIV. This is evident by the fact that some of them are falling pregnant, poor performance and drop-out from school. The focus of their teachers is more on Grade 11 and 12 learners, so female Grade 8 learners look for boys for attention. This shows little information is available for them and this paper is contributing to that body of knowledge. In order to achieve the objective of this paper, questions asked looked into the knowledge and attitudes of Grade 8 learners on burden diseases including HIV/AIDS, how learners make responsible choices about their lives, are they able to protect and prevent themselves from becoming infected with HIV/AIDS. The research was carried out in one district of the Eastern Cape Province in South Africa.

\section{Research Design and Methodology}

\subsection{Research Design}

This is a qualitative research in which the case study was used as views and feelings of learners were important to discover. An in-depth investigation of small number of participants was employed for instance, focus group discussions and unstructured interviews for in-depth understanding. The data are conserved in descriptive narrations like field notes and recording. According to Ref. [15], qualitative research is interesting in both unintended and intended consequences since it shows determination to identify the phenomenon. Qualitative researchers aim to acquire an in-depth of human behaviour.

\subsection{Population and Sample}

According to Ref. [16], a population is a group of elements or cases, whether individuals, objects, or events, which conform to specific criteria to which the researcher intends for sample of the target population. The population for this paper involved Grade 8 learners, out of thirty six (36) learners, twenty participants were selected by the researcher in one Senior Secondary school in the Education District, Circuit 9 from rural areas.

The purposive sampling was used to select information-rich individuals as the sample was judged to be typically of the population under investigation [17]. Also, the researcher selected particular elements from the population that is representative or information about the topic of interest. The purposive sampling is less to generalize to a larger population than it is to gain deeper understanding of the specific type. The sample was comprised of Grade 8 twenty participants drawn from the one selected school in the Mthatha Education District, Circuit 9. They were the mixture of boys and girls for instance twelve girls and eight boys.

\subsection{Instrumentation}

Qualitative data through FGD (focus group discussion) and semi-structured interviews were generated from the Grade 8 learners of the one Senior Secondary school of the rural area. Using FGD may have some advantage because it enabled the participants to come up with their deep sited opinions [18]. When using semi-structured interviews participants have the opportunity to permit free responses which could be recorded in the participants 
own words [19]. Interviews were recorded and field notes were taken. The aim of the qualitative interviews used in this paper was to acquire an in-depth understanding of the human behaviour and to investigate the how and why of decision making not just what, where and when for instance Grade 8 learners who are understanding the phenomenon. The interview questions were asked in such a way that the participants were able to give a detailed description of their experiences, feelings and views concerning the knowledge and attitudes about burden of diseases including HIV/AIDS. Interviews were carried on their school as this was where they felt comfortable. This permitted participants to feel free and promoted honest and open responses. Responses were transcribed after the interviews were completed [20]. The researcher retained all transcribed recordings for safe keeping so that the written responses could be used to validate the data.

\subsection{Data Analysis and Procedures}

All the collected data was studied and analyzed to unlock hidden information from raw data and transforming it into user friendly information and if any themes have formed [21]. After data was collected from the sample, they were grouped according to the responses, and then analyzed manually to regulate the effect of the responses. The researcher listened to the voice recorder and organized the data by breaking it into manageable units, synthesizing it, searching for patterns, discovering what is important to be learnt. The aim of the researcher was to create descriptive, multidimensional categories, which form a preliminary framework for analysis. Data were coded, units and categories were formed and patterns were recognized. The data were grouped into explication of themes and sub-themes and coded for easy Ref. [22]. Data were analyzed thematically.

\subsection{Ethical Considerations}

Permission to carry the study was received from the
Provincial Department of Education, the Mthatha education district and the principal of the sampled school. Participants agreed to participate in the study by completing the informed consent form. Participants were guaranteed of their confidentiality and anonymity. They were informed that they could withdraw from the study if they so desired. Fortunately, no one withdrew from the study.

\section{Findings and Discussion}

The procedures for analysis of qualitative data derived from the Focus Group Discussion interviews as well as interviews in the form of open-ended questions. Ref. [23], postulated that analysis involved "working with data, organizing it, breaking it down, synthesizing it, searching for patterns, discovering what is important and what is to be learned, and deciding who will tell others”. I therefore analyzed conversations from school learners by identifying themes upon patterns and ideas that emerged from the data.

The procedure that I used for the analysis of Focus Group data from learners was borrowed from phenomenology which is a philosophical strategy of analyzing data where priority is given to the actual words spoken by the participant [24]. The application of Focus Group Discussion as a data collection technique in qualitative research was a wise choice, especially as I was investigating the basic knowledge and attitudes to promote safe behaviours to Grade 8 learners concerning burden of diseases including HIV/AIDS. I followed by analyzing the data using the NMUs (natural meaning units) to represent specific thoughts, feelings or perceptions as expressed by the participant [25]. Each NMU was followed by the explication of each theme, so as to clearly explain the life world and everyday feelings and experiences of a particular individual hoped that by both description and explanation of each theme, a clear perspective of their practical experience would be revealed. The responses were shown by using the following Table 1: 
Table 1: Experiential statements of participants

\begin{tabular}{|l|l|}
\hline Learner & Natural meaning units \\
\hline $\begin{array}{l}\text { 1A. HIV/AIDS caused because people do not care for themselves. } \\
\text { Sometimes other e.g. boys sleep with girls and vise versa. }\end{array}$ & $\begin{array}{l}\text { She sees carelessness as the major cause that can make people } \\
\text { become easily infected by HIV and also the way teenagers } \\
\text { engage themselves in sexual activities. }\end{array}$ \\
\hline $\begin{array}{l}\text { B. Sometimes one can get HIV through blood e.g. may be in an } \\
\text { accident trying to help, unaware that she /he has a cut that may } \\
\text { contact with infected blood. Not use prevention measures like } \\
\text { gloves. By misbehaving, not to steak to their norms and values when } \\
\text { they are outside their homes. }\end{array}$ & $\begin{array}{l}\text { She contends that people are unaware on how they protect } \\
\text { themselves from being infected with HIV. Therefore, they need } \\
\text { to be educated. Many teenagers misbehave when they are away } \\
\text { from their families, they are not self-disciplined. }\end{array}$ \\
\hline $\begin{array}{l}\text { 2A. Abstinence comes first, I could say those who are married } \\
\text { should be faithful to one another and condomise. }\end{array}$ & $\begin{array}{l}\text { She strongly felt that, abstinence is the key prevention. Although } \\
\text { she also recommended that condoms should be used. Those who } \\
\text { are married should be faithful. }\end{array}$ \\
\hline $\begin{array}{l}\text { B. People should abstain or use condoms although they are } \\
\text { unreliable. }\end{array}$ & $\begin{array}{l}\text { This other respondent strongly disagrees with the use of } \\
\text { condoms because of their unreliability instead she argued that } \\
\text { people should abstain. }\end{array}$ \\
\hline $\begin{array}{l}\text { 3A. HIV is not the only infectious disease but there are those like } \\
\text { gonorrhoea, syphilis and STIs. }\end{array}$ & $\begin{array}{l}\text { HIV is not the only infectious disease and she continued by } \\
\text { enumerating others like gonorrhoea, syphilis and STIs. }\end{array}$ \\
\hline $\begin{array}{l}\text { B. People already heard or listened HIV/AIDS programs from many } \\
\text { sources e.g. radio, television, community meetings, church etc. }\end{array}$ & $\begin{array}{l}\text { Although people listen to radios and television, they also need to } \\
\text { be equipped with more knowledge about HIV/AIDS. }\end{array}$ \\
\hline
\end{tabular}

The findings revealed two thematic categories of learner behaviour, the undisciplined and accepted practices that marks the knowledge and attitudes of the Grade 8 learners to promote safe behaviours about the burden of diseases including HIV/AIDS as presented here:

- Lack of equal knowledge about HIV (opportunistic diseases)

- Lack of knowledge about awareness programmes

(1) Lack of equal knowledge about HIV (opportunistic diseases)

When the participants were responding to the question of their awareness about opportunistic diseases including HIV, they argued that they know and hear of some diseases.

I know the names of diseases for example, whooping cough, measles, HIV and diarrhoea (FGD 1).

HIV/AIDS is the most vulnerable and continuing disease, it is a continuing and incurable disease.

It was revealed that amongst all the diseases mentioned HIV/AIDS was regarded as the most vulnerable disease. At least it was shown that they know some of the diseases but they lack the knowledge of the opportunistic diseases related to HIV/AIDS. This has a negative impact on the lives of the learners generally.

This paper also reveals that in the absence of a cure, and in most areas in the absence of adequate treatment, HIV/AIDS diminishes or destroys quality of life before it takes away the life itself. As a result learners see their lives harder and difficult to cope with many things including school. It also emerged that one become infected at any age. This finding is in line with Ref. [25], that learners affected by HIV/AIDS at home or at school report feeling depressed, fearful and misunderstanding. Also, to reach the young before they are sexually active, sexually targeted, HIV education must begin early and extended throughout their school years. Attitudes and behaviours of the young people can be changed to reduce their risk of HIV infection. The lack of knowledge and attitudes about opportunistic diseases including HIV/AIDS especially in schools of rural areas is confirmed by this finding.

(2) Lack of knowledge about awareness programmes

Some Grade 8 learners lack basic knowledge about awareness programmes and that result to do unexpected things about their lives. Learners were unaware of the ways in which HIV infection can occur, and of the ways in which HIV infection can be prevented. The data revealed that education should ensure that Life-skills and HIV/AIDS should not be presented as an isolated learning content, but be integrated into the curriculum. This was recapped by 
on learner who said that:

"Witches can make one become infected, there are myths and misconceptions about HIV/AIDS (FGD 2).”

The themes or areas run concurrently from focus group discussion and natural meaning units and have emerged strongly. The conversation given above is, in a sense, a summary of the meanings conveyed and captured in the themes. The level of Grade 8 learners was found to be very low. Learners contend that they are not afraid of AIDS but of being diagnosed as HIV positive. It is difficult for them to more especially if they are not receiving enough information from both parents and Life Orientation teachers. This paper reveals that some Grade 8 learners are aware of HIV/AIDS; there are others who said it does not exist. It has also been highlighted that the phenomenon of learners having unprotected sex with folder men for money, as well as pupils saying they did not have time to use condoms.

Learners mentioned different types of diseases: “Gonorrhoea, HIV/AIDS, STIs and Syphilis". Amongst all the diseases mentioned, HIV/AIDS was regarded as the most vulnerable disease. "HIV/AIDS is the most vulnerable and continuing disease” The above statements from learners can be supported by Mishra [26] who argues that, in the absence of a cure, and in most areas in absence of adequate treatment, HIV/AIDS diminishes or destroys quality of life before it takes away life itself. Learners said that, as a result, their lives are harder and it is difficult to cope with many things including schools.

Learners also argued that there are prevention measures such as "abstinence and condomise and also married couples should be faithful to another" and Ref. [27] revealed that many young people become sexually active long before adults would prefer them to do so or expect them to receive education about HIV/AIDS and abstinence in the context of Life Skills education on an ongoing basis.

Learners also contend that, they received the information about HIV/AIDS from different sources for example, "radios, church, television and community meetings". Therefore, The South African Organization, Soul City was formed with the aim of developing productions to educate people including school children about health issues. In addition, learners argued that, "HIV/AIDS programmes should be introduced at an early stage”. Ref. [27], in support argued that HIV/AIDS programmes will be most effective when they are introduced before puberty, that is, before young people become sexually active.

Also, the findings [26], confirm argument that "HIV/AIDS programmes will be the most effective source of information introduced before puberty”. These programmes will help them to make the right decision about their lives. Also, the programmes are to promote healthy sexual behaviour among adolescents and to reduce the incidence of HIV/AIDS sexually transmitted diseases and teenage pregnancies. This finding supports the view by the then Ministry of Education [26], that, values and morality cut a cross language or the outward expressions of culture, our physical appearance, our age or sex or belief, that we cherish and live by, values that give meaning to our individual and social relationships, even our solitary spiritual journeys and our intellectual and imaginative excursions. This can help in solving the problems of learners who were not able to make the right choices about their lives and conscious of who one is and what life is about.

\section{Conclusions}

Regardless of the constant intervention by the Department of Education and teachers, learners still lack the basic knowledge and attitudes to promote safe behaviours on opportunistic diseases including HIV/AIDS. It was noted that HIV/AIDS is a disease that threatens the lives of all of us, a continuing growth disease that affects all spheres including school children. Learners should apply positive moral and values in the absence of elders to have a potential to bring about change in their behaviours. This paper 
reveals that learners have shown different acceptable and unacceptable behaviours that result sometimes to be unable to differentiate between what is right and what is wrong.

It is therefore recommended that pupils need to have role models, people they can look up to. In the absence of parents, it should be teachers' responsibility to advise the pupils and inform them about different types of diseases, opportunistic diseases including HIV/AIDS in schools. In most cases children who are school going age remain at a constant or increasing disadvantage with respect to knowledge about HIV/AIDS. The responsibility also lies with parents to address the issue of pregnancy and HIV/AIDS. Also, the Department of Education in all policy documents should encourage schools to become caring communities where parents and children can speak openly about HIV/AIDS. As a final point, the Ministry of Education in collaboration with the Ministry of Health to ensure that the national education system plays its part in stemming the spread of HIV/AIDS and ensures that the rights of all those infected and affected are fully protected. The basic knowledge about HIV/AIDS is an attempt to bring about change in behavioural patterns of teachers and parents.

Future studies that could investigate other research on this aspect within the same grade are advocated. A study focusing on both teachers and learners on their roles in teaching and learning Life Orientation subject is suggested. Also, a study looked on appropriate course content for pre-service and in-service training of teachers to cope with HIV/AIDS in schools.

\section{Limitations}

The study was limited to the one selected senior secondary school of the Mthatha education district. Not all Grade 8 learners were used and as a result findings presented in this paper cannot be generalised.

\section{References}

[1] Gellman, B. 2010. "West Refused to Lead to Early Warnings of Pandemic.” Tribute, (July 8/2010).
[2] The Department of Education. 2008. South African School Act no 84: South Africa.

[3] HEAIDS. 2008. "Being a Teacher in the Context of the HIV/AIDS Pandemic.” Pretoria: Higher Education South Africa.

[4] DOE. 2001. "National Policy on HIV/AIDS for Learners and Educators in Public Schools, and Students and Educators in Further Education and Training Institution.” National Education: Policy ACT No. 27 of 1996. Pretoria: Department of Education.

[5] Government Gazette. 1999. No, 20372: 1 (410)

[6] Mishra, R. C. 2011. HIV/AIDS Education. India: Charman Enterprises.

[7] HEAIDS. 2011. "Being a Teacher in the Context of the HIV/AIDS Pandemic.” Pretoria: Higher Education South Africa.

[8] Coombe, B. 2012. AIDS the challenge for South Africa. Cape Town: Human \& Rousseau and Tafelberg.

[9] Asmal, K. 1999. Policy Handbook for Educators. Labour Relations Council (ELRC). Pretoria: Universal Print Group.

[10] UNAIDS. 2009. "The Journal for African Women's Studies”. AIDS epidemic update.www.unaids.org (accessed 26 January 2009) USAID HIV/AIDS-Zambia 1 (1): 123-205

[11] DENOSA. 2012. "Nursing Update.” Journal for African Women's Studies 1 (1).

[12] SACMEQ. 2013. Research Report. Tanzania.

[13] Peter, F. 2010. Qualitative Research in Education. London. Franz Cronje. Gopsons Paper Ltd.

[14] McMillan, J. H. and Schumacher, S. 2007. Research in Education 6th ed. Evidence Based Inquiry: United States of America.

[15] McMillan, J. H. and Schumacher, S. 2009. Research in Education 6th ed. Evidence Based Inquiry: United States of America.

[16] Cohen, L. and Manion, K. 2011. Research Methods in Education. (4th edition). London: Routledge.

[17] Kane, E. G. 2011. The Practice of Social Research. Cape Town: Oxford University Press.

[18] Heath, P. R., 2010. “The P. K. Zone. A phenomenological Study.” Parapsychology 2 (64).

[19] Aanstoos, C. M. 2008. "A Phenomenological Study of Thinking." In Duquense Studies in Phenomenological Psychology, by A. Giorgi, A. Barton \& C. Maes, Duquense University Press.

[20] Ashworth, S. 2009. “HIV/AIDS Special Issue.” Journal of Education 38.

[21] Bogdan, R. C. and Biklein, S. K. 1982. Qualitative Research for Education: An Introduction to Theory Methods. Boston: Allyn and Bacon.

[22] Mwanje, J. I. 2001. "Qualitative Research Process, 

Concerning Burden of Diseases Including HIVIAIDS

Module 2.” Organisation for Social Studies: Eastern and Southern Africa (OSSREA).

[23] Heath, P. R., 2001. “The P. K. Zone. A phenomenological Study.” Parapsychology 2 (64).

[24] Caelers, D. 2006. Our Children Need Condoms at School. Cape Argus, September 6.

[25] UNAIDS. "The Journal for African Women's Studies (2007)”. AIDS epidemic update.www.unaids.org (accessed 26 January 2009) USAID HIV/AIDS-Zambia 1 (1).

[26] Asmal, K. 2001. Policy Handbook for Educators. Labour Relations Council (ELRC). Pretoria: Universal Print Group.

[27] UNAIDS. 2004. "The Journal for African Women's Studies)”. AIDS epidemic update.www.unaids.org (accessed 26 January 2009) USAID HIV/AIDS-Zambia 1(1): $123-205$ 